\title{
Análise Crítica dos Pressupostos e Fundamentos Conceituais da Escola de Psicossomática de Paris
}

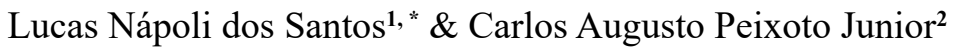 \\ ${ }^{1}$ Faculdade Pitágoras de Governador Valadares, Governador Valadares, MG, Brasil \\ ${ }^{2}$ Pontifícia Universidade Católica do Rio de Janeiro, Rio de Janeiro RJ, Brasil
}

\begin{abstract}
RESUMO - Este artigo apresenta uma análise crítica do quadro teórico da Escola de Psicossomática de Paris. Pretendese demonstrar a hipótese de que tal matriz conceitual está sustentada em uma concepção iluminista de subjetividade, que concebe o corpo como algo a ser dominado pela mente. Argumenta-se que tal concepção se manifesta de forma implícita na hipótese defendida pelos autores dessa escola, segundo a qual a vulnerabilidade do indivíduo ao adoecimento somático seria resultante de uma insuficiência fundamental ou passageira do funcionamento mental. Demonstra-se que tal enunciado é herdeiro da concepção de psiquismo formulada no âmbito da metapsicologia freudiana, na qual a mente é entendida como um aparelho destinado a possibilitar a descarga de excitações, sobretudo as provenientes do próprio corpo (pulsionais).
\end{abstract}

PALAVRAS-CHAVE: psicossomática, psicanálise, Escola de Psicossomática de Paris

\section{Critical Analysis of the Conceptual Foundations of Paris Psychosomatic School}

\begin{abstract}
This paper presents a critical analysis of the theoretical framework of the Paris Psychosomatic School. It intends to demonstrate the hypothesis that such conceptual framework is supported in an Enlightenment conception of subjectivity, which sees the body as something to be dominated by the mind. It argues that such a view is expressed by the hypothesis held by the authors of this school, according to which the vulnerability of the person to somatic illness occurs because of a fundamental or passing failure of mental functioning. It shows that such a statement is heir of the conception of psyche formulated within Freudian metapsychology, in which the mind is understood as a device designed to enable the discharge of excitement, especially that from the body itself (instinctual excitement).
\end{abstract}

KEYWORDS: psychosomatic, psychoanalysis, Paris Psychosomatic School

A tentativa de traduzir a complexidade do real em leis e mecanismos universais é um dos traços mais notáveis da racionalidade científica moderna, estrutura de explicação do mundo cujas raízes remontam à filosofia clássica grega, mas que se consolida, sobretudo, a partir do século XVI, impulsionada pelo pensamento de Bacon, Descartes e Newton (Martins, 1999). Herdeira de tal racionalidade, a medicina moderna, também chamada de científica, imaginou-se capaz de discernir a complexidade do adoecer humano, adotando como guia o axioma de que uma doença só se constitui como tal à medida em que existem alterações anátomo-fisiológicas subjacentes aos sintomas. Essa concepção reducionista atinge seu clímax no século XIX
(Canguilhem, 2009; Foucault, 2008), mas permanece vigente na atualidade através de outras roupagens (Santos, 2013).

Consequência desse reducionismo é a dificuldade (ou resistência) experimentada pela medicina desde o século XIX, na abordagem de enfermidades nas quais não é possível verificar a existência de um substrato orgânico. Trata-se de doenças nas quais o psiquismo, e não o corpo, assume o lugar de protagonista do mal-estar, ainda que o sofrimento se manifeste por meio de queixas de ordem somática (Guedes, Nogueira, \& Camargo Jr., 2006, 2008, 2009). Esse era o caso, por exemplo, da histeria na virada do século XIX para o XX (Freud, 1910/1996).

*E-mail: lucasnapolipsicanalista@gmail.com 
Nessa época, a ausência de alterações anátomofisiológicas no quadro histérico levava boa parte da comunidade médica a suspeitar da veracidade dos sintomas apresentados pelo paciente (Freud, 1956[1886]/1996). Na primeira de suas Cinco Lições de Psicanálise, ministradas na Clark University, em 1909, Freud (1910/1996) comenta o desafio que as manifestações histéricas representaram para o saber médico no final do século XIX:

O médico que, por seus estudos, adquiriu tantos conhecimentos vedados aos leigos, pode formar uma ideia da etiologia das doenças e de suas lesões [...] Em face, porém, das particularidades dos fenômenos histéricos, todo o seu saber e todo o seu preparo em anatomia, fisiologia e patologia deixamno desamparado. (p. 29)

A desconfiança quanto à veracidade da sintomatologia histérica acabou sendo estendida para as tentativas de compreensão e tratamento da histeria feitas a partir de métodos não ortodoxos, como a hipnose. Jean-Martin Charcot, por exemplo, um dos mestres de Freud no período pré-psicanalítico, foi alvo de várias críticas, por certa ala da comunidade médica, por utilizar a hipnose como técnica de investigação e tratamento da histeria (Freud, 1956[1886]/1996). Nota-se, portanto, que, no alvorecer do século XX, não havia um clima favorável à recepção de quaisquer ideias que privilegiassem uma abordagem psicológica do adoecimento (Albuquerque, 2015).

Assim, para sustentar a tese de que os sintomas corporais dos pacientes histéricos possuíam causalidade psíquica e poderiam ser tratados através de uma psicoterapia, Freud teve que enfrentar uma forte oposição de muitos de seus colegas que nutriam a esperança de que, no futuro, fosse possível se descobrir as bases orgânicas da histeria. De todo modo, ao insistir obstinadamente em remeter os sintomas somáticos daquele distúrbio a conteúdos psíquicos, o psicanalista vienense acabou colocando em xeque o reducionismo organicista cultivado pelo campo médico, abrindo espaço para a investigação do papel exercido pelos fatores psíquicos na constituição de certas doenças (Albuquerque, 2015).

Não obstante, muitos anos antes de o fundador da psicanálise iniciar seus estudos sobre a histeria, o médico alemão Johann Christian August Heinroth, em 1818, já defendia a tese de que patologias orgânicas poderiam ser provocadas por elementos de natureza anímica. Fundamentado em concepções que misturavam religião e ciência, Heinroth acreditava que as doenças físicas poderiam ser o resultado de um processo de degeneração da alma, provocado por uma vida pecaminosa (Steinberg, HermannLingen, \& Himmerich, 2013). A despeito dessa interpretação moralizante do adoecimento, o pensamento de Heinroth tem sido considerado relevante na medida em que, na aurora da medicina moderna, propõe uma visão ampla do processo saúde-doença que não contempla apenas fatores anátomo- fisiológicos. Além disso, a obra do autor testemunha uma das primeiras aparições do termo psicossomática na literatura médica.

Apesar de ter trabalhado com a hipótese de que, na histeria, os sintomas de natureza corporal seriam provocados por fatores psíquicos inconscientes, Freud nunca utilizou a expressão doença psicossomática para caracterizar a neurose histérica (Nicolau, 2008). Em vez disso, o médico vienense forjou o termo conversão para se referir ao mecanismo que tornaria possível a expressão de um conflito psíquico através de um sintoma somático. Para Freud (1894/1996), os distúrbios físicos da histeria seriam resultado da transformação do afeto, originalmente vinculado às representações mentais recalcadas em algo de natureza somática.

Contudo, é importante assinalar que os sintomas somáticos da histeria, via de regra, não possuem substrato orgânico. Nesse sentido, poder-se-ia dizer que, nesse caso, o corpo afetado é o corpo tomado em sua dimensão simbólico-imaginária e não o corpo real - para utilizar uma classificação de inspiração lacaniana (Lacan, 1972-73/1985). Por conseguinte, haveria uma diferença radical entre a conversão histérica e o que se costuma chamar atualmente de doenças psicossomáticas, pois, no caso dessas, geralmente é possível encontrar uma lesão orgânica subjacente aos sintomas.

É importante mencionar ainda que, no início de sua carreira como clínico, Freud tratava de outras patologias, distintas da histeria, nas quais também havia queixas somáticas relacionadas a variáveis de natureza subjetiva ou, no mínimo, comportamental. Tratava-se dos distúrbios que o autor denominou de neuroses atuais, por oposição às chamadas neuroses de defesa (histeria, neurose obsessiva, fobia e psicose). Na categoria de neuroses atuais, estariam compreendidas a neurose de angústia e a neurastenia, ambas caracterizadas por queixas tanto psíquicas, quanto somáticas. $\mathrm{O}$ traço que faria com que fossem agrupadas numa mesma categoria seria a existência de um mesmo fator etiológico preponderante, a saber: uma vida sexual insatisfatória (Freud, 1898/1996).

Por considerar que os sintomas tanto psíquicos quanto físicos das neuroses atuais fossem tão somente o resultado de uma espécie de "refluxo" da libido insatisfeita no corpo, ou seja, um processo eminentemente orgânico, Freud não acreditava que o método terapêutico que vinha desenvolvendo naquele momento (a psicanálise) fosse recomendável para o tratamento daqueles distúrbios. Afinal, a terapia psicanalítica era colocada em prática a partir do pressuposto de que os sintomas apresentados pelo paciente seriam símbolos de conflitos inconscientes. No caso das neuroses atuais, não haveria tal expressão simbólica, mas a manifestação de uma descarga direta de excitação sexual (Freud, 1898/1996).

Descrente do potencial terapêutico da psicanálise para os casos de neurose atual, Freud acabou abandonando 
a investigação desse tipo de doença e concentrou-se exclusivamente nas neuroses de defesa. Por outro lado, a hipótese de que a terapia psicanalítica seria eficaz apenas no tratamento desse último grupo de patologias fez com que o médico não explorasse a aplicação da psicanálise em outros contextos do campo da saúde. Essa tarefa, contudo, acabou sendo realizada por outros analistas, alguns contemporâneos de Freud, outros posteriores a ele (Casetto, 2006).

\section{O ADOECIMENTO SOMÁTICO EM GRODDECK, FERENCZI E ALEXANDER}

Entre os contemporâneos, destacam-se os nomes de Georg Groddeck, Sándor Ferenczi e Franz Alexander. Groddeck (1866-1934), um médico generalista, diretor de um sanatório para doentes crônicos na cidade alemã de Baden-Baden, foi pioneiro na aplicação da psicanálise no tratamento de doenças orgânicas. É relevante assinalar que, antes mesmo de conhecer a psicanálise, Groddeck já praticava com seus pacientes um tipo de abordagem das doenças muito semelhante ao que Freud desenvolvia em Viena. Assim como seu colega austríaco, Groddeck tomava os sintomas das enfermidades como símbolos de intenções, desejos e pensamentos presentes numa dimensão absolutamente inconsciente do ser, à qual ele denominava de Isso ("Es", em alemão). Também, de modo semelhante ao adotado por Freud em relação ao seu Inconsciente, Groddeck conduzia o tratamento tendo como objetivo levar o paciente a reconhecer os conteúdos que o Isso expressaria através dos sintomas (Groddeck, 1994).

Quando toma conhecimento das pesquisas de Freud, Groddeck (1994) sente, inicialmente, inveja por não ter recebido o mesmo reconhecimento do colega, mas, pouco tempo depois, decide escrever uma carta a ele, iniciando uma frutífera parceria de trabalho. Nessa primeira carta, Groddeck narra um breve histórico de suas descobertas e experimentos clínicos e pergunta a Freud se poderia considerar-se um autêntico psicanalista. O médico vienense autoriza o colega a apresentar-se como tal e se entusiasma com os resultados terapêuticos relatados por ele, estimulando-o a prosseguir a investigação acerca da aplicação da psicanálise no tratamento de doenças orgânicas.

Do ponto de vista teórico, Groddeck trabalhava com a hipótese de que não haveria uma diferença fundamental entre doenças psíquicas (como as neuroses de defesa) e doenças orgânicas. Para ele, em ambos os casos, tratar-se-ia da expressão do Isso (ou Inconsciente) ${ }^{1}$, a distinção estaria apenas na forma de manifestação (Groddeck, 1994).

1 Nesse primeiro contato com a obra de Freud, Groddeck acreditava que o seu Isso e o Inconsciente de Freud pudessem ser tomados como sinônimos (Groddeck, 1917/1992). Posteriormente, ao longo de sua obra, o médico alemão estabelecerá distinções entre os dois conceitos, considerando o Inconsciente como um dos elementos que compõem o Isso (Groddeck, 1926/1994). Por outro lado, a partir da publicação do trabalho "Das Ich und das Es" ("O Eu e o Isso"), Freud (1923/1996), alegando ter sido influenciado por Groddeck, passa a utilizar o termo Isso, mas num sentido radicalmente distinto do empregado pelo colega de Baden-Baden. De fato, enquanto o Isso groddeckiano pretende contemplar a totalidade dos processos e forças em atuação no indivíduo, o Isso freudiano é tomado como uma espécie de reservatório das pulsões, ou seja, trata-se de uma
Sándor Ferenczi (1873-1933), analista húngaro que se notabilizou no campo psicanalítico por seus experimentos terapêuticos, que iam de encontro ao tratamento psicanalítico clássico, também manifestou sua ousadia téorico-clínica ao propor a aplicação da psicanálise em outros setores da medicina. Para ele, a terapia psicanalítica seria eficaz não apenas no tratamento das neuroses de defesa, mas também na abordagem de um tipo particular de neuroses cujos sintomas se aglutinariam ao redor de determinado órgão do corpo, lesionando-o. Trata-se do que o autor denomina de neuroses de órgão. $\mathrm{O}$ fator etiológico fundamental nessas patologias seria a utilização excessiva do órgão em questão como veículo de prazer erótico. Isso aconteceria porque todas as partes do corpo humano seriam potencialmente erógenas. Não obstante, a saúde física dependeria da existência de certo equilíbrio na distribuição da libido entre as regiões do corpo. A concentração de energia sexual em determinado órgão impediria o mesmo de exercer suas funções fisiológicas de sobrevivência, ocasionando a doença (Ferenczi, 1926/2011).

O também húngaro Franz Alexander (1891-1964) foi um dos pioneiros, juntamente com Félix Deutsch e Helen Dunbar, na fundação do campo interdisciplinar que ficou conhecido como medicina psicossomática. Deutsch e Alexander emigraram para os Estados Unidos entre o final da década de 1920 e início da década de 1930. Enquanto Deutsch se fixou em Boston, Alexander radicou-se em Chicago, onde pôde se dedicar ao estudo das correlações entre algumas enfermidades e certas variáveis de natureza subjetiva.

Tal investigação já vinha sendo desenvolvida pela psicanalista nova-iorquina Dunbar, que desenvolvia suas pesquisas adotando como hipótese a possível existência de traços de personalidade comuns entre pacientes de diversas doenças. Alexander, no entanto, postulava que são conflitos emocionais específicos e não características gerais da personalidade que estão associadas diretamente ao surgimento de certas doenças (Casetto, 2006).

No artigo "The Development of Psychosomatic Medicine", de 1962, Alexander expõe, de forma clara, suas concepções acerca da relação entre estados emocionais e doenças orgânicas. A hipótese básica com a qual o autor trabalha é a de que conflitos emocionais recorrentes tendem a provocar um estado de estresse crônico sobre o organismo, provocando efeitos fisiológicos cumulativos

redução do Isso proposto por Groddeck a uma dimensão puramente energética. 
que, por sua vez, podem dar origem a doenças reversíveis ou irreversíveis.

Segundo Alexander (1962), a partir das investigações clínicas realizadas no âmbito do Instituto Psicanalítico de Chicago, foi verificada a existência de padrões emocionais específicos associados a determinadas doenças. Inicialmente, foram encontradas tais regularidades em sete enfermidades: úlcera duodenal, colite ulcerativa, asma, hipertensão essencial, artrite reumatoide, tireotoxicose e neurodermatite. $\mathrm{O}$ autor, contudo, faz a ressalva de que nem sempre os indivíduos que apresentavam os padrões emocionais em questão se tornavam doentes.
Por essa razão, Alexander (1962) não encarava os conflitos emocionais crônicos como fatores etiológicos suficientes para a eclosão de uma doença. Para o autor, a enfermidade só aconteceria a partir do encontro entre dois fatores: uma vulnerabilidade orgânica (genética, congênita ou adquirida) e uma vulnerabilidade emocional para certas situações interpessoais específicas. A orientação das investigações de Alexander, que privilegia a busca por associações entre certos perfis subjetivos e determinadas patologias, se tornou o traço mais característico da matriz teórica conhecida em psicossomática, como Escola de Chicago.

\section{A ESCOLA DE PSICOSSOMÁTICA DE PARIS}

A partir do início da década de 1950, alguns analistas da Sociedade Psicanalítica de Paris, notadamente Pierre Marty, Michel de M'Uzan, Michel Fain e Christian David começaram a publicar trabalhos cujas temáticas estavam localizadas na interface entre a psicanálise e a medicina psicossomática. Seguindo a tendência da Escola de Chicago de traçar os perfis subjetivos que estariam relacionados diretamente a certas doenças, esses primeiros trabalhos buscavam demonstrar a existência de uma organização subjetiva específica que tornaria certos indivíduos vulneráveis a doenças ou sintomas somáticos.

Verificou-se que o elemento comum entre os casos analisados em diferentes investigações era a existência de uma insuficiência profunda ou passageira do funcionamento mental. Em outras palavras, por razões de natureza circunstancial ou estrutural, o aparelho psíquico dos pacientes analisados não teria capacidade suficiente para manejar os fluxos de excitação que a ele convergem. Assim, o corpo funcionaria como uma espécie de "válvula de escape" dessa quantidade de excitação que não pôde ser elaborada, ocasionando o surgimento da doença (Marty, 1993).

As postulações teóricas e as diretrizes clínicas que decorrem dessa hipótese central constituem o quadro conceitual da chamada Escola de Psicossomática de Paris (Aisenstein, 2006), que acabou se tornando a matriz teórica predominante no que concerne à abordagem do adoecimento somático no campo psicanalítico. Essa hegemonia se mostra evidente, sobretudo, na literatura brasileira, quando se observa um número muito maior de trabalhos em que essa concepção ocupa um lugar de destaque, em comparação com o lugar reservado a outras formas de pensar o adoecimento, como as propostas por Groddeck, Ferenczi e Alexander².

Apesar dessa hegemonia, atualmente, o modelo teórico proposto por Pierre Marty e seus colegas também vem

2 Para maiores detalhes desta hegemonia no Brasil, $c f$., por exemplo, Ongaro (1994), Vieira (1997), Ferraz (1997, 2007, 2010), Peres (2001, 2006), Peres \& Santos (2005a, 2005b, 2009), Peres, Caropreso \& Simanke (2015), Capitão \& Carvalho (2006), Bandeira \& Barbieri (2007), Filgueiras, Lisboa, Macedo, Paiva, Benfica, \& Vasques (2007) recebendo críticas que sugerem certa insuficiência de suas proposições no plano da clínica. À guisa de ilustração, podemos citar as críticas de Dejours (2007), Bronstein (2011) e Press (2015).

No texto "Biologia, psicanálise e somatização", Dejours (2007) relata que perdeu a confiança no quadro teórico da Escola de Psicossomática de Paris, após uma experiência trágica com um paciente que sofrera um grave adoecimento somático. De fato, o referido doente apresentava o que Marty e seus colegas chamariam de um nível excelente de mentalização, o que levou Dejours a descartar a hipótese de que ele pudesse vir a padecer uma enfermidade orgânica grave. Assim, o autor alega ter percebido que a tese de que o bom nível de funcionamento mental impede o corpo de sofrer uma patologia física precisaria ser, no mínimo, relativizada.

Bronstein (2011), por sua vez, questiona uma das principais diretrizes clínicas do modelo francês, qual seja, a necessidade de introduzir modificações na técnica psicanalítica, especificamente para atender pacientes que apresentam doenças somáticas. Para a autora, os aspectos a serem levados em conta na abordagem desses pacientes, como a capacidade de simbolização e a adaptação da técnica às necessidades do paciente são elementos que devem ser observados no tratamento de qualquer pessoa. É possível interpretar essa crítica como um questionamento também da separação estrutural entre quadros de adoecimento somático e outras formas de sofrimento psíquico - distinção postulada por Marty e seus colegas.

Jacques Press (2015), analista cuja formação em Psicossomática ocorreu justamente no âmbito da Escola de Psicossomática de Paris, chama a atenção para a tendência medicalizante, que se faria presente na atuação clínica baseada no modelo teórico francês. Para o autor, essa atuação seria orientada por uma nosologia sintomática que faria referência ao grau de mentalização do paciente, mas negligenciaria os elementos de natureza contratransferencial que evidentemente se fazem presentes na relação entre o médico e o doente. Nesse sentido, o modelo teórico 
proposto por Marty (1993) e seus colegas daria ensejo a uma abordagem objetificante do paciente, própria da medicina contemporânea, mas inteiramente avessa ao campo psicanalítico.

Nota-se que as críticas que Dejours (2007), Bronstein (2011) e Press (2015) dirigem ao quadro teórico da Escola de Psicossomática de Paris contemplam algumas proposições e consequências clínicas do modelo, mas não fazem referência aos fundamentos ontológicos que o sustentam. Por outro lado, é possível formular a hipótese de que as limitações apontadas pelos autores derivam, justamente, dos pressupostos que fundamentam o modelo como um todo.

Este artigo apresenta uma análise crítica do quadro teórico da Escola de Psicossomática de Paris, com o objetivo de demonstrar a hipótese de que a abordagem do adoecimento somático, proposta pelos autores dessa escola, está fundamentada em uma concepção iluminista de subjetividade. Nesse sentido, os principais conceitos, argumentos e inferências elaborados por Marty e outros teóricos serão avaliados com a finalidade de evidenciar sua afiliação a pressupostos característicos da ideologia iluminista, como o dualismo mente-corpo.

A relevância deste trabalho está, justamente, em tornar visíveis as premissas ontológicas de uma matriz teórica psicanalítica - procedimento que permite verificar a maior ou menor proximidade do quadro teórico em questão com outras matrizes do campo psicanalítico e de outros saberes.

\section{O Quadro Teórico da Escola de Psicossomática de Paris}

A fim de contextualizar as críticas que pretendemos desenvolver aos pressupostos que sustentam a matriz teórica proposta pela Escola de Psicossomática de Paris, é conveniente examinar, com alguma profundidade, três conceitos fundamentais para a concepção dos processos que, de acordo com essa escola, estão relacionados ao surgimento de um adoecimento somático. Trata-se das noções de pensamento operatório, depressão essencial e desorganização progressiva.

A noção de pensamento operatório foi introduzida em 1962, por Pierre Marty e Michel de M’Uzan, num relatório apresentado no $23^{\circ}$ Congresso dos Psicanalistas de Línguas Romanas. De acordo com os autores, o conceito precisava ser introduzido para designar um tipo de funcionamento mental marcado pela ausência de atividade fantasmática (Marty \& M’Uzan, 1963). No relatório, Marty e M'Uzan tomaram, como ponto de partida, uma comunicação anterior feita por Michel Fain e Christian David ("Aspects fonctionnels de la vie onirique"), em que os autores defendem a tese de que o processo de construção dos sonhos, na medida em que promove a ligação das excitações pulsionais a representações, protegeria o corpo de ser impactado por essas tensões.
Marty e M'Uzan (1963), por seu turno, argumentam que não apenas a produção onírica, mas também a atividade fantasmática como um todo exerceria essa função de continência das intensidades pulsionais através da simbolização. Para demonstrar essa hipótese, os autores assinalam que, nos indivíduos que padecem de doenças orgânicas, verifica-se, justamente, uma ausência dessa atividade fantasmática e o desenvolvimento de um tipo de funcionamento, o pensamento operatório, voltado exclusivamente para a realidade externa, ou seja, sem conexão com conteúdos internos de ordem fantasmática:

Essa função de integração comum à atividade onírica e à atividade fantasmática, nada nos permite melhor saber de sua importância do que certos pacientes psicossomáticos nos quais ela está ausente ou se encontra gravemente alterada. [...] $\mathrm{O}$ fato é que nos pacientes psicossomáticos, a carência de atividade fantasmática - ao menos do ponto de vista funcional - está associada ao desenvolvimento de uma forma de pensar bastante original, que nós propomos chamar de pensamento operatório

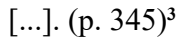

Em termos metafóricos, o pensamento operatório poderia ser comparado a um maquinário desprovido de lubrificação, à medida que seus conteúdos não seriam investidos pela libido, servindo, unicamente, para descrever e ilustrar as ações do sujeito e os acontecimentos externos. Os sonhos de pacientes que apresentam pensamento operatório, por exemplo, seriam geralmente repetitivos, pobres e relacionados apenas com a vida atual do sujeito. Esse tipo de funcionamento subjetivo estaria associado ao adoecimento somático, à medida que seria um efeito da insuficiência fundamental do aparelho psíquico. Incapaz de lidar adequadamente com as excitações, a mente exerceria uma função meramente instrumental e mecânica (Marty \& M’Uzan, 1963).

Em trabalhos posteriores, Marty (1993) substituiu o termo pensamento operatório por vida operatória, pois se verificou que o caráter mecânico observado inicialmente, no âmbito mental, pode estender-se também para o domínio do comportamento.

O conceito de depressão essencial também emergiu da investigação clínica de pacientes que sofriam de doenças somáticas. Assim como a noção de pensamento operatório, a depressão essencial também é entendida como um processo tributário da insuficiência do funcionamento mental. No livro publicado em 1963, L'investigation psychosomatique, Marty, M'Uzan e David descreveram um tipo específico de depressão, que se manifestava em associação ao adoecimento orgânico e que se caracterizava pela ausência tanto de objeto, quanto de sintomas clássicos da melancolia, como as autoacusações e a culpa. Nesse primeiro momento, esse quadro clínico foi chamado de depressão sem objeto ou depressão psicossomática (Marty, 1993).

3 Todas as traduções dos textos originalmente publicados em francês são de nossa lavra. 
O termo depressão essencial só viria a aparecer em 1966, em um artigo da autoria de Marty (1966). Tal expressão foi escolhida porque, do ponto de vista do autor, esse tipo de depressão se caracterizaria pelo sintoma mais básico de todo o processo depressivo: o rebaixamento do tônus libidinal. A diferença em relação à depressão clássica estaria na inexistência de uma compensação a esse rebaixamento, no que diz respeito à distribuição da libido no psiquismo.

Em outras palavras, seria como se a libido simplesmente desaparecesse, o que explicaria precisamente o desencadeamento dos fenômenos que caracterizam o pensamento operatório, isto é, ausência de vida onírica e fantasmática e o funcionamento meramente instrumental do aparelho psíquico. Essa espécie de desaparecimento da libido na depressão essencial, levou Marty à hipótese de que essa afecção seria uma manifestação inequívoca da pulsão de morte (Marty, 1966).

Em um texto posterior, de 1980, "L'Ordre psychosomatique", o autor afirma que a depressão essencial possui uma etiologia traumática. Tratar-se-ia de um dos efeitos da desorganização funcional, provocada pela incapacidade do psiquismo de lidar com o fluxo excessivo de excitações em jogo no trauma. Por essa razão, a depressão essencial seria geralmente precedida de angústias difusas, as quais não teriam a função de alarme, geralmente atribuída a tais afetos. Essas angústias já seriam o indicativo de que o volume de excitações teria transbordado a capacidade de elaboração do aparelho psíquico (Marty, 1993).

Assim como a noção de depressão essencial, o conceito de desorganização progressiva também foi introduzido por Marty no ano de 1966, no XXVII Congresso de Psicanalistas de Línguas Romanas. A comunicação apresentada pelo autor, posteriormente publicada na Revista Francesa de Psicanálise, chamava-se "Un processus majeur de somatisation; la désorganization progressive". No texto, Marty demonstra que, em função dos resultados encontrados a partir da investigação clínica de pacientes que apresentavam adoecimento somático grave, foi necessário elaborar um novo conceito para caracterizar um processo de desorganização psíquica e somática distinto das regressões, já conhecidas no campo psicanalítico (Marty, 1993).

Com efeito, a regressão libidinal, tal como descrita inicialmente por Freud (1917a/1996), possui um caráter patológico, na medida em que promove um abandono das organizações libidinais mais maduras, mas também apresenta um potencial de reorganização, pois não inviabiliza a retomada do processo de amadurecimento. Por outro lado, Marty (1993) afirma que os processos aparentemente regressivos, verificados nos casos de desorganização progressiva, seriam amiúde definitivos, ou seja, teriam um caráter eminentemente destrutivo.

Nas regressões típicas, haveria sempre um sistema (o estágio de fixação libidinal) que "frearia" o processo de desorganização, impedindo que ele continuasse avançando e comprometendo a saúde do indivíduo. Na desorganização progressiva, por outro lado, haveria uma verdadeira destruição da organização libidinal e, consequentemente, uma desorganização do psiquismo como um todo. Marty (1993) postula que se trata, assim como na depressão essencial, de uma manifestação inequívoca da pulsão de morte desintrincada da pulsão de vida.

É preciso assinalar que a noção de desorganização progressiva, assim como a de regressão, pressupõe uma concepção evolutiva da subjetividade. De fato, para Marty, tanto o psiquismo, quanto o corpo se desenvolvem de modo concomitante, em um processo de hierarquização funcional. A desorganização progressiva trabalharia num sentido oposto ao dessa hierarquização, levando o indivíduo, por essa razão, não só a uma perda significativa da capacidade de elaboração mental, mas também ao adoecimento somático (Marty, 1993).

À luz da análise desses três conceitos fundamentais para a matriz teórica da Escola de Psicossomática de Paris, é possível concluir que a doença orgânica seria um dos efeitos de um processo mais amplo de desorganização psicossomática, que teria sua origem na ação direta da pulsão de morte, dissociada da pulsão de vida. O potencial desagregador da pulsão de morte levaria à destruição da organização psicossomática conquistada ao longo do desenvolvimento, ao esvaziamento de libido no aparelho psíquico e à perda de atividade fantasmática, ocasionando, respectivamente, a desorganização progressiva, a depressão essencial e o pensamento operatório.

Apesar de todo o processo global que culmina no advento do adoecimento somático ter, como ponto de partida, a desintrincação pulsional e a consequente ação direta da pulsão de morte, aquilo que poderíamos qualificar como sendo a causa "proximal" da doença orgânica, do ponto de vista da Escola de Psicossomática de Paris, seria a insuficiência do funcionamento mental.

Tanto a riqueza de representações de palavra e representações de coisa, quanto as interações entre elas no pré-consciente caracterizam o que Marty (1993) denomina de uma boa mentalização, a qual seria um fator de proteção em relação ao surgimento do adoecimento somático. Para o autor, é o sistema pré-consciente o responsável por promover a articulação entre o registro sensório-motor e a linguagem, ou seja, possibilitar a ligação entre as representações de coisas e as representações de palavra (Marty, 2001). Por essa razão, Marty (1993) considera a avaliação do préconsciente como uma estratégia clínica fundamental para a compreensão e a abordagem do adoecimento somático a partir da psicanálise:

Poder-se-ia finalmente dizer que, quanto mais o Pcs [préconsciente] de um sujeito se mostrar rico de representações permanentemente ligadas entre si, mais a patologia eventual correrá o risco de se situar na vertente mental. Quanto menos o Pcs de um sujeito se mostrar rico de representações, de ligações entre as que existem e de permanência das representações e de suas ligações, mais a patologia eventual correrá o risco de se 
situar na vertente somática. É nesse sentido que qualificamos o Pcs de 'peça central' da economia psicossomática. (p. 28)

Na má mentalização, haveria poucas representações no pré-consciente ou a associação entre as que existem ocorreria de uma maneira muito pobre. Nesse caso, as representações de palavra poderiam, eventualmente, apresentar um estatuto de representações de coisa na medida em que poderiam perder seu potencial associativo, servindo apenas como "testemunhos de eventos registrados" (Marty, 1993, p. 26). Reduzidas a tal função, essas representações não se mostrariam capazes de servir como veículos para a tradução dos movimentos do Inconsciente, fazendo com que esses só pudessem encontrar expressão através do comportamento.

Marty (1993) defende a ideia de que o adoecimento somático seria sempre uma consequência do descompasso entre o indivíduo e as condições ambientais em que se encontra. $\mathrm{O}$ autor reconhece que tal desarmonia está sempre presente em alguma medida, de modo que, desde o início do desenvolvimento, a relação do indivíduo com o ambiente está condicionada a um processo de adaptação. Não obstante, para se adaptar, o indivíduo precisaria lançar mão de recursos específicos.

Do ponto de vista do analista francês (Marty, 1993), tais recursos pertencem a três grandes domínios: o aparelho somático, o aparelho mental e os comportamentos (ação). Dos três, o menos maleável é, evidentemente, o primeiro. Por essa razão, o aparelho somático seria o último domínio utilizado pelo indivíduo para se adaptar. O corpo só responderia ao processo de adaptação se os comportamentos e os mecanismos mentais não estivessem disponíveis.

Tal situação pode se dar de modo circunstancial ou se constituir no padrão de funcionamento do indivíduo. Em outras palavras, um indivíduo com um aparelho mental suficientemente amadurecido pode passar por situações traumáticas, que excedem sua capacidade de elaboração mental e, por conta disso, lançar mão dos comportamentos ou do corpo como recursos adaptativos. Nesse caso, o aparelho mental tenta obstruir o processo de desorganização, ensejado pela situação traumática através dos diversos mecanismos de defesa (deslocamento, condensação, projeção etc.), mas fracassa nessa tarefa, em função do nível elevado de excitações. Há outros casos, contudo, em que o aparelho mental do indivíduo não está preparado sequer para fazer esse primeiro combate, fazendo com que o comportamento e, sobretudo, o corpo tornem-se os recursos primários de adaptação a situações traumáticas.

No primeiro caso, em que os indivíduos apresentam uma boa mentalização, as doenças somáticas que eventualmente surjam em função da utilização do corpo como último recurso adaptativo costumam ser reversíveis na medida em que geralmente são derivadas de um processo de "regressão somática". Isso não significa que indivíduos bem mentalizados estejam absolutamente imunes a doenças somáticas graves, de difícil recuperação (Marty, 1993).
O fator determinante, para Marty (1993), é o nível de excitações com o qual o aparelho psíquico precisa lidar. A tese central, aqui, é a de que o corpo só fala quando a mente se cala ou está muda. Nesse segundo caso, o dos indivíduos mal mentalizados, as doenças tendem a ter um caráter evolutivo, ou seja, de difícil reversão. Trata-se agora, para Marty, de um processo de desorganização psicossomática e não de regressão.

\section{A herança Freudiana da Escola de Psicossomática de Paris}

Marty (1993) também se dedicou a estabelecer as diferenças entre as patologias somáticas, resultantes de processos de desorganização progressiva e regressão somática e os sintomas conversivos da histeria. Do ponto de vista do autor, as primeiras não possuiriam valor simbólico, não seriam eroticamente investidas e tampouco funcionariam como formações de compromisso que solucionam um conflito psíquico. Além disso, o recalque, mecanismo de base da neurose histérica, não seria o responsável pelos sintomas das somatizações.

Por essa razão, a psicoterapia dessas afecções não estaria fundamentada na interpretação. Alguns autores como Ferraz (1997, 2010), Laplanche e Pontalis (1992) e Quintella (2003) consideram que essa diferenciação, formulada por Marty (1993), recupera a distinção feita por Freud entre as psiconeuroses e as neuroses atuais. Nesse sentido, as concepções da Escola de Psicossomática de Paris poderiam ser consideradas herdeiras do modelo freudiano de abordagem das neuroses atuais.

De fato, do ponto de vista de Freud (1895/1996), as neuroses atuais seriam resultado justamente de uma insuficiência do aparelho psíquico, no manejo da soma de excitação sexual acumulada no organismo. Em um artigo de 1895, intitulado "Sobre os fundamentos para destacar da neurastenia uma síndrome específica denominada 'neurose de angústia"”, Freud enuncia essa hipótese após verificar que os sintomas da neurose de angústia (um dos tipos de neurose atual) costumam ser acompanhados por uma redução do desejo sexual. Ao cotejar tal observação com a constatação de que a neurose de angústia seria desencadeada justamente em decorrência de uma impossibilidade de descarga sexual completa, Freud (1895/1996) chega à seguinte conclusão:

Todas essas indicações - de que estamos diante de um acúmulo de excitação; de que a angústia, provavelmente correspondente a essa excitação acumulada, é de origem somática, de modo que o que se está acumulando é uma excitação somática; e ainda, de que essa excitação somática é de natureza sexual é acompanhada por um decréscimo da participação psíquica nos processos sexuais - todas essas indicações, dizia eu, levam-nos a esperar que o mecanismo da neurose de angústia deva ser buscado numa deflexão da excitação sexual somática da esfera psíquica e no consequente emprego anormal dessa excitação. (p. 108) 
Nota-se, portanto, que a hipótese de que a incapacidade do psiquismo de representar as excitações endógenas (noção que posteriormente dará lugar ao conceito de pulsão na obra freudiana) favoreceria o surgimento de uma desordem de natureza somática já se fazia presente no modelo freudiano de compreensão das neuroses atuais. Nesse sentido, nos parece justificada a tese de que tal modelo pode ter funcionado, de fato, como um ponto de partida para a abordagem do adoecimento somático, promovida pelos teóricos da Escola de Psicossomática de Paris.

Nas duas espécies de neuroses atuais analisadas por Freud, neurastenia e neurose de angústia, o elemento responsável pela produção dos sintomas seria o acúmulo de tensão sexual no corpo, acompanhado da ausência de um trabalho psíquico sobre essa soma de excitação. Como vimos, Freud (1895/1996) observara que, à medida que a excitação sexual permanecia concentrada no corpo, o psiquismo deixava de participar dos processos sexuais. A conclusão, portanto, fora a de que a psique se mostraria insuficiente para manejar tamanha quantidade de excitação.

Nesse sentido, os sintomas das neuroses atuais seriam o resultado tanto do acúmulo de tensão sexual no corpo, quanto da insuficiência do psiquismo em dar vazão a tal soma de excitação. Portanto, tais afecções não apresentariam uma consistência simbólica, pois não seriam frutos dos processos de deslocamento e condensação (próprios da esfera psíquica), mas a expressão direta dos efeitos “tóxicos" da concentração de excitação sexual no organismo (Freud, 1912/1996, 1917b/1996).

\section{Crítica aos Pressupostos da Escola de Psicossomática de Paris}

A hipótese de que o adoecimento somático seria determinado, em última instância, pela insuficiência de mecanismos mentais no manejo das excitações, possui como pressuposto fundamental, um modelo de abordagem da subjetividade em que o psiquismo é tomado metaforicamente como um aparelho. Trata-se de uma representação da mente como uma máquina, cuja função primordial é a de fornecer circuitos através dos quais a energia proveniente das excitações experimentadas pelo organismo, sobretudo as internas (pulsionais), possa ser descarregada. Esse aspecto evidencia, com extrema clareza, a presença da metapsicologia freudiana no quadro teórico da Escola de Psicossomática de Paris.

Como se sabe, a concepção da mente como um aparelho é um dos elementos fundamentais da parte metapsicológica da teoria freudiana. Embora Freud tenha formulado diversas concepções de psiquismo ao longo de sua obra, o modelo privilegiado pelo autor, no âmbito de suas especulações metapsicológicas, é aquele no qual a psique é concebida a partir da metáfora da máquina. Com efeito, em uma de suas primeiras tentativas de formular uma teoria geral do funcionamento psíquico, o Projeto para uma Psicologia
Cientifica, o autor enuncia a tese de que a mente possuiria a função primordial de descarregar excitações: "Um sistema nervoso primário se vale dessa Qn [quantidade de excitação], assim adquirida, para descarregá-la nos mecanismos musculares através das vias correspondentes e, desse modo, se mantém livre do estímulo. Essa descarga representa a função primária do sistema nervoso" (Freud, $1950[1895] / 1996$, p. 348)

Baretta (2007) argumenta que esse ponto de vista freudiano acerca do funcionamento do psiquismo é profundamente influenciado pela fisiologia do século XIX, sobretudo pelo emprego de conceitos como os de arco reflexo e irritabilidade, que já vinham sendo usados naquela época para explicar o funcionamento do organismo. Por essa razão, o autor defende que toda a metapsicologia freudiana está fundamentada no pressuposto de que o psiquismo é, tal como o organismo para a fisiologia do século XIX, uma "substância irritável". Com efeito, ao tratar do psiquismo sob o prisma metapsicológico, Freud, de fato, atribui à mente $\mathrm{o}$ estatuto de substância, na medida em que a concebe como um ente distinto que recebe, contém e elimina excitações. Em seu último texto teórico, o "Esboço de Psicanálise", o autor formula essa tese de maneira inequívoca: "Presumimos que a vida mental é função de um aparelho ao qual atribuímos a característica de ser extenso no espaço e de ser constituído de diversas partes." (Freud, 1940/1996, p. 158)

Ao formalizar o conceito metapsicológico de pulsão (Trieb; Freud, 1915/1996) como uma força constante proveniente do corpo, o psiquismo passa a ser pensado como um aparelho organizado fundamentalmente para manejar as intensidades pulsionais. $\mathrm{O}$ autor observa que a natureza constante do fluxo pulsional demanda um funcionamento mental mais complexo do que aquele exigido pelos demais estímulos. Um simples movimento reflexo não seria suficiente para promover o restabelecimento do equilíbrio psíquico, já que as intensidades pulsionais não cessariam de se manifestar, obrigando a mente a "renunciar à sua intenção ideal de afastar os estímulos" (Freud, 1915/1996, p. 126). Em decorrência disso, o aparelho psíquico seria obrigado a colocar em ação um verdadeiro trabalho sobre as intensidades, a fim de manejá-las e impedir que exerçam um efeito traumático. Esse trabalho seria feito, fundamentalmente, a partir das representações mentais e dos processos associativos entre elas.

Marilia Aisenstein (2010), uma das principais representantes contemporâneas da Escola de Psicossomática de Paris, assinala que a tese freudiana, de que a pulsão faz uma exigência contínua de trabalho representacional à mente, permite esclarecer o que estaria em jogo no adoecimento somático. De acordo com a autora, os sintomas orgânicos seriam "consequências de uma impossibilidade da psique de decodificar ou traduzir as exigentes demandas do corpo" (Aisenstein, 2010, p. 53). Por essa razão, Aisenstein considera o conceito freudiano de pulsão como uma noção crucial para a abordagem do adoecimento somático, na 
medida em que, nesse tipo de afecções, as intensidades pulsionais manifestar-se-iam em estado bruto, isto é, sem um trabalho prévio de representação.

Nesse contexto, as representações mentais atuariam como meios através dos quais o processo de elaboração poderia ser levado a cabo. Em decorrência disso, a hipótese de insuficiência do funcionamento mental como fator determinante da vulnerabilidade individual ao adoecimento orgânico só pode ser compreendida adequadamente se considerarmos esse modelo mecânico de psiquismo como referencial teórico fundamental.

Cremos que essa concepção acerca da origem e dos processos subjacentes ao adoecimento somático reproduz, inadvertidamente, um conhecido dito popular cujo enunciado geralmente é expresso da seguinte forma: "Quando a cabeça não pensa, o corpo padece". Tanto essa concepção popular das relações entre corpo e mente, quanto a matriz teórica da Escola de Psicossomática de Paris estão fundamentadas em, pelo menos, duas ideologias modernas: o dualismo e o iluminismo.

De fato, o aforismo popular é dualista, na medida em que concebe a cabeça (mente) como algo essencialmente distinto do corpo. É, também, iluminista, pois postula uma concepção em que a mente possui a função ativa de elaboração das experiências, ao passo que o corpo seria apenas a substância passiva que sofre os efeitos dessa elaboração. Assim, podemos considerar o ditado "Quando a cabeça não pensa, o corpo padece" como uma espécie de tradução popular tanto da concepção dualista, sistematizada por René Descartes, no século XVII, quanto da ideologia iluminista que vê, na razão, a luz que ilumina a escuridão em que a natureza (corpo) supostamente tende a nos deixar (Luz, 1988).

Outro corolário que pode ser extraído do referido adágio é a ideia de que o pensamento (a razão) só é produzido no âmbito da mente (cabeça). O corpo padeceria justamente porque não seria capaz de exercer nenhum papel na produção dos pensamentos, mas tão somente sofreria as consequências de sua (não) elaboração. Nesse sentido, o corpo seria impotente frente às intensidades afetivas, necessitando da mente (razão) para ser "salvo" dos possíveis efeitos traumáticos das experiências. Ora, é precisamente esse o argumento sustentado por dois dos principais teóricos da Escola de Psicossomática de Paris, Michel Fain e Christian David (Fain \& David, 1963 citado por Marty \& M’Uzan, 1963).

No já mencionado artigo, $O$ pensamento operatório, Marty e M’Uzan (1963) fazem alusão ao relatório apresentado por Fain e David no $23^{\circ}$ Congresso dos Psicanalistas de Línguas Romanas, em que os autores defendem a tese de que a atividade onírica, isto é, um processo de elaboração psíquica, protegeria o organismo ao promover a ligação de forças "que teriam o risco de provocar perturbações profundas no soma" (Fain \& David, 1963 citado por Marty \& M’Uzan, 1963, p. 345). Essa citação deixa claro que, do ponto de vista desses autores, o bom funcionamento dos mecanismos de elaboração psíquica -o que Marty (1993) denomina de "mentalização" - seria um fator de proteção do corpo frente aos efeitos potencialmente destrutivos da pulsão.

Peres, Caropreso e Simanke (2015), em estudo dedicado a demonstrar a importância da noção de representação na metapsicologia freudiana e no quadro teórico da Escola de Psicossomática de Paris, afirmam que "A psicossomática psicanalítica parte do pressuposto de que o trabalho psíquico é a mais efetiva defesa do organismo frente às tensões"4 (p. 171). Analisando o raciocínio dos autores, é possível concluir que o corpo precisaria se submeter ao domínio da mente, a fim de se prevenir contra as tensões que, curiosamente, têm origem no próprio corpo na medida em que advêm da incidência das pulsões, como foi dito anteriormente. Em outras palavras, a mente deve sujeitar o corpo como forma de defendê-lo de si mesmo.

Em uma análise mais profunda e de inspiração genealógica (Nietzsche, 1887/2009), o que se verifica tanto na concepção de adoecimento somático, proposta pela Escola de Psicossomática de Paris quanto na matriz metapsicológica freudiana é a presença de certo repúdio pela dimensão do corpo. Com efeito, a ideia de que, na ausência de mecanismos mentais suficientes, a estimulação advinda do corpo (pulsão) irá voltar-se contra o próprio indivíduo, ocasionando o surgimento de patologias, evoca, do nosso ponto de vista, uma concepção de corpo como algo perigoso e potencialmente explosivo. Corpo-bomba que demandaria uma máquina mental suficientemente forte para controlá-lo e evitar uma implosão (adoecimento). Ora, não é a descrição precisa da orientação ética presente no pensamento platônico: agir de tal modo que a razão prevaleça sobre o corpo?

Cremos ter demonstrado, portanto, que o modelo teórico proposto pela Escola de Psicossomática de Paris, para a abordagem do adoecimento somático, é herdeiro das formulações freudianas acerca das neuroses atuais. De fato, é possível afirmar que, de certo modo, Marty e seus colegas expandiram a hipótese freudiana de explicação das neuroses atuais para outras patologias orgânicas. Por essa razão, as premissas teóricas que sustentavam o modelo freudiano acabaram sendo integralmente adotadas pela Escola de Psicossomática de Paris, sem qualquer tipo de questionamento. Assim, a compreensão do funcionamento psíquico através da analogia com uma máquina de descarga de tensões provenientes do corpo, bem como a tese de que um funcionamento mental suficientemente potente protege o corpo contra sua autodestruição, se impuseram como os fundamentos da matriz teórica da Escola de Psicossomática de Paris.

4 Essa citação evidencia o lugar hegemônico que a Escola de Psicossomática de Paris ocupa na literatura brasileira que trata do adoecimento somático de um ponto de vista psicanalítico. Com efeito, nota-se que os autores reduzem a "psicossomática psicanalítica" ao quadro teórico francês. 
Demonstramos, também, que tais fundamentos, embora tenham sido derivados do modelo freudiano, são, na verdade, premissas presentes em um quadro teóricoideológico mais amplo, que neste trabalho qualificamos como iluminista. Trata-se, com efeito, da racionalidade vigente na modernidade, a qual concebe a associação entre corpo e mente a partir do mesmo raciocínio utilizado para analisar a relação entre natureza e cultura. Assim, como a natureza é vista por essa racionalidade como ameaçadora, o corpo, supostamente a parcela de natureza em nós, também é tomado como potencialmente perigoso. Nesse sentido, da mesma forma que a cultura deveria prevalecer sobre a natureza, domando-a, controlando-a, domesticando-a, a mente também deveria dominar o corpo, protegendo-o de se autodestruir com a intensidade excessiva de seus afetos.
Vimos que esse modo de analisar as relações entre corpo e mente se encontra, ainda, tão arraigado na cultura ocidental que o próprio senso comum o reproduz através de adágios como "Quando a cabeça não pensa, o corpo padece".

Apesar da obviedade, cremos ser necessário frisar que se trata, aqui, tão-somente de uma leitura possível da matriz teórica da Escola de Psicossomática de Paris. Leitura de matiz genealógico que, por essa razão, pretendeu tornar visível a possível dinâmica dos afetos, que se faz presente de forma implícita nos enunciados teóricos. Com efeito, em consonância com tal orientação metodológica, não se pode deixar de mencionar, aqui, o desejo que estimulou este trabalho, a saber: o de promover, através da crítica de um modelo hegemônico, a abertura a outras formas de pensar sobre o adoecimento orgânico em psicanálise.

\section{REFERÊNCIAS}

Aisenstein, M. (2006). The indissociable unity of psyche and soma: A view from the Paris Psychosomatic School. The International Journal of Psychoanalysis, 87(3), 667-680. doi:10.1516/0VBX-1HGY-T86R-P5CB

Aisenstein, M. (2010). The mysterious leap of the somatic into the psyche. M. Aisenstein \& E. R. Aisemberg (Eds.), Psychosomatics today: A psychoanalytic perspective (pp. 4762). London: Karnac Books.

Albuquerque, K. M. (2015). Freud, a racionalidade médica e a constituição do objeto psicopatológico na Psicanálise: Um estudo epistemológico. Estudos Interdisciplinares em Psicologia, 6(1), 54-64. Recuperado de http://pepsic. bvsalud.org/scielo.php?script $=$ sci_arttext\&pid $=$ S2236$64072015000100005 \& \operatorname{lng}=$ pt\&tlng $=\overline{p t}$.

Alexander, F. (1962). The development of psychosomatic medicine. Psychosomatic Medicine, 24(1), 13-24. Recuperado de http://journals.lww.com/psychosomaticmedicine/ Citation/1962/01000/The_Development_of_Psychosomatic Medicine .4.aspx

Bandeira, M. F., \& Barbieri, V. (2007). Personalidade e câncer de mama e do aparelho digestório. Psicologia: Teoria e Pesquisa, 23(3), 295-304. http://dx.doi.org/10.1590/S010237722007000300008.

Baretta, J. P. F. (2007). Existência e aparelho psíquico: A crítica ontológica da psicanálise freudiana com base na analitica da existência de Martin Heidegger (Tese de Doutorado). Núcleo de Práticas Clínicas, Pontifícia Universidade Católica de São Paulo, São Paulo, SP, Brasil. Recuperado de https://tede2. pucsp.br/handle/handle/15637

Bronstein, C. (2011). On psychosomatics: The search for meaning. The International Journal of Psychoanalysis, 92(1), 173-195. https://doi.org/10.1111/j.1745-8315.2010.00388.x

Capitão, C. G., \& Carvalho, É. B. (2006). Psicossomática: Duas abordagens de um mesmo problema. Psic: Revista da Vetor Editora, 7(2), 21-29. Recuperado de http://pepsic.bvsalud. org/scielo.php?pid=S1676-73142006000200004\&script $=$ sci arttext

Casetto, S. J. (2006). Sobre a importância de adoecer: Uma visão em perspectiva da psicossomática psicanalítica no século XX.
Psychê, 10(17), 121-142. Recuperado de http://pepsic.bvsalud. org/scielo.php?pid=S1415-11382006000100008\&script $=$ sci_ arttext

Dejours, C. (2007). Biologia, psicanálise e somatização. InR. M. Volich; F. C. Ferraz, \& M.A.A.C.A. Arantes (Orgs.), Psicossoma II: Psicossomática Psicanalítica (pp. 45-57). São Paulo, SP: Casa do Psicólogo

De M’Uzan, M., Marty, P., \& David, C. (1963). L'investigation psychosomatique. Paris: PUF.

Ferenczi, S. (2011). As neuroses de órgão e seu tratamento. In S. Ferenczi, Edição standard brasileira das obras psicológicas completas de Sigmund Freud (2a ed., Vol. 3, pp. 413-419). São Paulo, SP: Editora WMF Martins Fontes. (Trabalho original publicado em 1926)

Ferraz, F. C. (1997). Das neuroses atuais à psicossomática. In F. C. Ferraz \& R. M. Volich (Orgs.), Psicossoma: Psicossomática psicanalítica (pp. 23-38). São Paulo, SP: Casa do Psicólogo.

Ferraz, F. C. (2007). A tortuosa trajetória do corpo na psicanálise. Revista Brasileira de Psicanálise, 41(4), 66-76. Recuperado de http://pepsic.bvsalud.org/scielo.php?pid=S0486641X2007000400007\&script=sci_arttext\&tlng=en

Ferraz, F. C. (2010). A somatização no campo da psicopatologia não-neurótica. Revista da SBPH, 13(2), 176-191. Recuperado de http://pepsic.bvsalud.org/scielo.php?pid=S1516$08582010000200002 \&$ script $=$ sci arttext

Filgueiras, M. S. T., Lisboa, A. V., Macedo, R. M. D., Paiva, F. G. D., Benfica, T. M. S., \& Vasques, V. A. (2007). Avaliação psicossomática no câncer de mama: Proposta de articulação entre os níveis individual e familiar. Estudos de Psicologia(Campinas), 24(4), 551-560. http://dx.doi. org/10.1590/S0103-166X2007000400014.

Foucault, M. (2008). O nascimento da clínica (6a ed.). Rio de Janeiro, RJ: Forense Universitária.

Freud, S. (1996). As neuropsicoses de defesa. In S. Freud, Edição standard brasileira das obras psicológicas completas de Sigmund Freud (J. Salomão, trad., Vol. 3, pp. 49-72). Rio de Janeiro, RJ: Imago. (Trabalho original publicado em 1894)

Freud, S. (1996). Sobre os fundamentos para destacar da neurastenia uma síndrome específica denominada "neurose de angústia". 
In S. Freud, Edição standard brasileira das obras psicológicas completas de Sigmund Freud (J. Salomão, trad., Vol. 3, pp. 89118). Rio de Janeiro, RJ: Imago. (Trabalho original publicado em 1895)

Freud, S. (1996). A sexualidade na etiologia das neuroses. In S. Freud, Edição standard brasileira das obras psicológicas completas de Sigmund Freud (J. Salomão, trad., Vol. 3, pp. 247-270). Rio de Janeiro, RJ: Imago. (Trabalho original publicado em 1898)

Freud, S. (1996). Cinco Lições de Psicanálise. In S. Freud, Edição standard brasileira das obras psicológicas completas de Sigmund Freud (J. Salomão, trad., Vol. 11, pp. 15-65). Rio de Janeiro, RJ: Imago. (Trabalho original publicado em 1910)

Freud, S. (1996). Contribuições a um debate sobre a masturbação. In S. Freud, Edição standard brasileira das obras psicológicas completas de Sigmund Freud (J. Salomão, trad., Vol. 12, pp. 257-272). Rio de Janeiro, RJ: Imago. (Trabalho original publicado em 1912)

Freud, S. (1996). Os instintos e suas vicissitudes. In S. Freud, Edição standard brasileira das obras psicológicas completas de Sigmund Freud (J. Salomão, trad., Vol. 14, pp. 115-144). Rio de Janeiro, RJ: Imago. (Trabalho original publicado em 1915)

Freud, S. (1996). Conferência XXII: Algumas ideias sobre desenvolvimento e regressão - etiologia. In S. Freud, Edição standard brasileira das obras psicológicas completas de Sigmund Freud (J. Salomão, trad., Vol. 16, pp. 343-360). Rio de Janeiro, RJ: Imago. (Trabalho original publicado em 1917a)

Freud, S. (1996). Conferência XXIV: O estado neurótico comum. In S. Freud, Edição standard brasileira das obras psicológicas completas de Sigmund Freud (J. Salomão, trad., Vol. 16, pp. 379-392). Rio de Janeiro, RJ: Imago. (Trabalho original publicado em 1917b)

Freud, S. (1996). O Ego e o Id. In S. Freud, Edição standard brasileira das obras psicológicas completas de Sigmund Freud (J. Salomão, trad., Vol. 19, pp. 15-80). Rio de Janeiro, RJ: Imago. (Trabalho original publicado em 1923)

Freud, S. (1996). Esboço de psicanálise. In S. Freud, Edição standard brasileira das obras psicológicas completas de Sigmund Freud (J. Salomão, trad., Vol. 23, pp. 152-229). Rio de Janeiro, RJ: Imago. (Trabalho original publicado em 1940)

Freud, S. (1996). Projeto para uma psicologia científica. In S. Freud, Edição standard brasileira das obras psicológicas completas de Sigmund Freud (J. Salomão, trad., Vol. 1, pp. 333-454). Rio de Janeiro, RJ: Imago. (Trabalho original publicado em 1950[1895])

Freud, S. (1996). Relatório sobre meus estudos em Paris e Berlim. In S. Freud, Edição standard brasileira das obras psicológicas completas de Sigmund Freud (J. Salomão, trad., Vol. 1, pp. 3549). Rio de Janeiro, RJ: Imago. (Trabalho original publicado em 1956[1886])

Guedes, C. R., Nogueira, M. I., \& Camargo Jr., K. R. (2006). A subjetividade como anomalia: contribuições epistemológicas para a crítica do modelo biomédico. Ciência \& Saúde Coletiva, 11(4), 1093-1103. https://dx.doi.org/10.1590/S141381232006000400030

Guedes, C. R., Nogueira, M. I., \& Camargo Jr., K. R. (2008). Os sintomas vagos e difusos em biomedicina: Uma revisão da literatura. Ciência \& Saúde Coletiva, 13(1), 135-144. https:// dx.doi.org/10.1590/S1413-81232008000100018

Guedes, C. R., Nogueira, M. I., \& Camargo Jr., K. R. (2009). Os sofredores de sintomas indefinidos: Um desafio para a atenção médica?. Physis: Revista de Saúde Coletiva, 19(3), 797-815. https://dx.doi.org/10.1590/S0103-73312009000300014
Groddeck, G. (1992). Condicionamento psíquico e tratamento de moléstias orgânicas pela psicanálise. In G. Groddeck, Estudos psicanalíticos sobre psicossomática (pp. 09-28). São Paulo, SP: Perspectiva. (Trabalho original publicado em 1917)

Groddeck, G. (1994). O homem e seu isso. São Paulo, SP: Perspectiva.

Groddeck, G. (1994). O Isso e a Psicanálise. In G. Groddeck, $O$ homem e seu isso (pp. 185-193). São Paulo, SP: Perspectiva. (Trabalho original publicado em 1926)

Lacan, J. (1985). O seminário, livro 20: Mais, ainda. Rio de Janeiro: Jorge Zahar. (Trabalho original publicado em 1972-1973)

Laplanche, J. \& Pontalis, J.-B. (1992). Neurose atual. In J. Laplanche \& J.-B. Pontalis, Vocabulário da Psicanálise (pp. 299-301). São Paulo, SP: Martins Fontes.

Luz, M. (1988). Natural, racional, social: Razão médica e racionalidade cientifica moderna. Rio de Janeiro, RJ: Editora Campus.

Martins, A. (1999). Novos paradigmas e saúde. Physis, 9(1), 83-112. Recuperado de http://www.scielo.br/pdf/physis/v9n1/04.pdf

Marty, P. (1966). La dépression essentielle. Revue Française de Psychanalyse, 32(3), 594-599.

Marty, P. (1980). L'ordre psychosomatique. Paris: Payot.

Marty, P. (1993). A psicossomática do adulto. Porto Alegre: Artes Médicas Sul.

Marty, P. (2001). La psychosomatique en 1981. Revue française de psychosomatique, 19(1), 161-171. doi : 10.3917/rfps.019.0161

Marty, P., \& de M'Uzan, M. (1963). La pensée opératoire. Revue Française de Psychanalyse, 27, 1345-1356.

Nicolau, R. F. (2008). A psicossomática e a escrita do real. Revista Mal Estar e Subjetividade, 8(4), 959-990. Recuperado de http:// pepsic.bvsalud.org/scielo.php?script=sci_arttext\&pid=S1518$61482008000400006 \& \operatorname{lng}=$ pt\&tlng $=$ pt.

Nietzsche, F. (2009). Genealogia da moral: Uma polêmica. São Paulo, SP: Companhia das Letras. (Trabalho original publicado em 1887)

Ongaro, S. (1994). Compreendendo as relações entre o psiquismo e o adoecer. Temas em Psicologia, 2(2), 167-175. Recuperado de: http://pepsic.bvsalud.org/scielo.php?pid=S1413389X1994000200017\&script=sci_arttext\&tlng=en

Peres, R. S. (2001). O papel das representações psíquicas no processo de somatização. Psicologia em Estudo, 6(1), 95-96. http://dx.doi.org/10.1590/S1413-73722001000100013

Peres, R. S. (2006). O corpo na psicanálise contemporânea: Sobre as concepções psicossomáticas de Pierre Marty e Joyce McDougall. Psicologia Clínica, 18(1), 165-177. http://dx.doi. org/10.1590/S0103-56652006000100014

Peres, R. S., \& Santos, M. A. D. (2005a). Pensamento operatório, desorganização progressiva e somatização: considerações sobre a psicossomática psicanalítica de Pierre Marty. Tempo Psicanalítico, 37, 207-227. Recuperado de http://bases.bireme. $\mathrm{br} /$ cgi-bin/wxislind.exe/iah/online/?IsisScript $=$ iah/iah.xis\&src $=$ google \&base $=$ LILACS\&lang $=$ p\&nextAction $=1$ nk\&exprSea $\mathrm{rch}=477523 \&$ indexSearch $=$ ID

Peres, R. S., \& Santos, M. A. D. (2005b). Carência fantasmática de vulnerabilidade somática em pacientes onco-hematológicos com indicação para o transplante de medula óssea. Psicologia Hospitalar, 3(1), 85-101. Recuperado de http://pepsic.bvsalud. org/scielo.php?pid=S1677-74092005000100006\&script=sci arttext\&tlng=en

Peres, R. S., Caropreso, F., \& Simanke, R. T. (2015). A noção de representação em psicanálise: da metapsicologia à psicossomática. Psicologia Clínica, 27(1), 161-174. http:// dx.doi.org/10.1590/0103-56652015000100009 
Press, J. (2015). Metapsychological and clinical issues in psychosomatics research. The International Journal of Psychoanalysis, 97(1), 89-113. doi: 10.1111/1745-8315.12334

Quintella, R. R. (2003). A neurose atual e a psicossomática no campo psicanalítico. Pulsional. Revista de Psicanálise, 16(169), 33-39. Recuperado de http://www.editoraescuta.com.br/ pulsional/169_04.pdf

Santos, L. (2013). A doença como manifestação da vida: Georg Groddeck e um novo modelo de cuidado em saúde. Curitiba: Prismas.

Steinberg, H., Herrmann-Lingen, C., \& Himmerich, H. (2013). Johann Christian August Heinroth: Psychosomatic medicine eighty years before Freud. Psychiatria Danubina, 25, 11-16.
Recuperado de http://www.hdbp.org/psychiatria_danubina/ $\mathrm{pdf} / \mathrm{dnb}$ vol25 no1/dnb vol25 no1 11.pdf

Vieira, W. C. (1997). A psicossomática de Pierre Marty. In F. C. Ferraz \& R. M. Volich (Orgs.), Psicossoma: Psicossomática psicanalítica (pp. 15-22). São Paulo, SP: Casa do Psicólogo.

Submetido: $10 / 07 / 2015$

Revisado: 01/02/2018

Aceito: $19 / 02 / 2018$ 